\title{
Experiment and Modeling of Void Discharges Within Dielectric Insulation Material Under Impulse Voltage
}

\author{
H. A. Illias, M. A. Tunio, H. Mokhlis \\ Department of Electrical Engineering \\ Faculty of Engineering, University of Malaya, 50603 Kuala Lumpur, Malaysia \\ G. Chen \\ The Tony Davies High Voltage Laboratory, University of Southampton \\ SO17 1BJ United Kingdom \\ and A. H. A. Bakar \\ UM Power Energy Dedicated Advanced Centre (UMPEDAC) \\ Level 4, Wisma R\&D, University of Malaya, 59990 Kuala Lumpur, Malaysia
}

\begin{abstract}
The presence of cavity in motor insulation fed by variable speed drive is one of the sources of partial discharge (PD) occurrence, especially under impulse voltage. This is a serious problem as PD can accelerate degradation of the motor insulation. Therefore, it is important to prevent void discharges from occurring in motor insulation under impulse voltage. In this work, the characteristics of void discharges within dielectric insulation material under impulse voltage were investigated through experiment and modeling. The test object consists of a rectangular void within a polyethylene material. The test object was stressed with different peak magnitude, front time and tail time of the applied impulse voltage. The experimental results were reproduced by simulation results from a void discharge model in insulation material. From the model that was developed, a better understanding on physical parameters that influence the characteristics of void discharges within dielectric material under impulse voltage can be attained.
\end{abstract}

Index Terms - Partial discharge, electrical insulation, dielectric material, high voltage engineering.

\section{INTRODUCTION}

THE existent of cavity within motor insulation fed by variable speed drive is one of the sources of partial discharge (PD) phenomena, especially under impulse voltage. The occurrences of PD are a serious problem because they can accelerate degradation of the motor insulation. Insulation degradation may reduce the quality of the insulation, shortening its lifetime. Therefore, it is important to prevent void discharges from occurring in motor insulation fed by variable speed drive. To enhance the understanding of discharges in motor insulation, experimental works on PD activities using impulse voltage have been performed extensively since the past.

Numerous works have been done in the past on partial discharge (PD) experiment in dielectric materials under impulse voltage [1-5]. Under impulse and AC voltages, a study on $\mathrm{PD}$ mechanism in a silicone gel using point plane geometry was studied in [1]. It was reported that under impulse voltage, the first

Manuscript received on 23 July 2014, in final form 14 October 2014, accepted 31 December 2014. discharge found in a virgin sample is due to the streamer initiation and propagation, which features are close to discharge in viscous liquids. The results obtained also show that streamers in gels are similar in hydrocarbon and silicone liquids, where there are two types of streamers in positive polarity, single type of streamer in negative polarity and similar inception voltage. Under impulse voltage, the main difference of discharge characteristics in gels and liquids in terms of self-healing has been identified.

An experimental work on surface discharge over $\mathrm{SF}_{6} /$ epoxy under impulse voltage was conducted to replicate discharge measurement in gas insulated switchgear [2,3]. The inception voltage, maximum discharge magnitude and time lag as a function of gas pressure were analyzed. The results show that the number of discharges under oscillating impulse voltage was higher than $\mathrm{AC}$ voltage due to the displacement current produced by oscillation. The oscillating impulse voltage was also recommended as the best waveform for the field impulse withstand test since it has the lowest impulse ratio.

Comparison between a high frequency ultra wide band and (HFUWB) low frequency selective wide band (LFSWB) PD 
detection systems was performed to study PD under impulse voltage, which replicates a switching device output [4]. The work reported that the HFUWB systems are unable to yield right information on the severity of the degradation and the PD intensity. However, obtaining reliable quantities was possible with good output signal optimization of the LFSWB system.

Discharge occurrence under impulse voltage was used to study the energy in tree channel formation [5]. The energy in a tree channel formation was reported due to formation of the electric field from conducting channel shorted some of the field, which is regarded as the energy available to form a breakdown channel under impulse voltage. The balance of energy was used to establish criteria for formation of channel. Through the approach taken, under impulse voltage, the minimum channel length for single channel formation and the breakdown channel radius were able to be determined.

Although numerous works have been performed on discharges in dielectric materials under impulse voltage, modeling of void discharges under impulse voltage is less likely to be found. Therefore, in this work, the characteristics of void discharge occurrences within dielectric material under impulse voltage were investigated through experiment and simulation. The purpose is to replicate void discharge occurrences in motor insulation fed by variable speed drive. The experiment test object consists of a rectangular void within a polyethylene insulation material. The test object was stressed with different peak magnitude, front time and tail time of the applied impulse voltage. A discharge model was developed using finite element method to simulate discharge occurrences under impulse voltage. Comparison between simulation and measurement results from the model was performed to identify physical parameters that influence the characteristics of void discharges within dielectric material. Through this work, a better understanding on void discharge characteristics within dielectric materials under impulse voltage may be attained.

\section{VOID DISCHARGE MODELING}

The void discharge model that was developed is shown in Figure 1, which is a three-dimensional (3D) model geometry in finite element method. The model consists of a rectangular void, located in the middle of a polyethylene (PE) dielectric material, as shown in Figure 1a. The void length is $6 \mathrm{~mm}$ and its height is $2 \mathrm{~mm}$ while the PE layer has a $6 \mathrm{~mm}$ height and $5 \mathrm{~cm}$ diameter. The upper layer of the dielectric material was applied with an impulse voltage while the lower surface was kept grounded. The void permittivity was set as 1 since it consists of air and the polyethylene permittivity as 2.25 . The model was solved for its electric field distribution to determine the occurrence of discharges within the void.

From this model, discharges may occur anywhere in the void region randomly due to the electric field distribution is uniform in the whole void for virgin void. Since the void size is large, a discharge may not affect the whole void surface [6,7]. Thus, in this model, the surface of the void was separated into 9 regions of equal surface area, where $A_{1}=A_{2}=A_{9}$, as shown in Figure 1b. The purpose of this division is to model discharge occurrences within certain area of the void surface. A discharge in a void is (a)
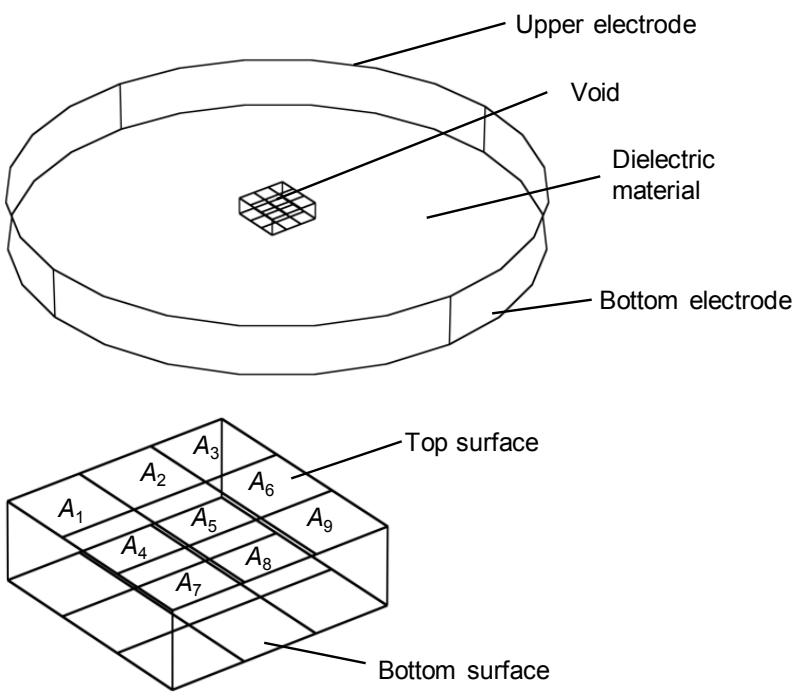

(b)

Figure 1. (a) Three-dimensional model geometry; (b) The rectangular void

commonly assumed to bridge from one surface to the other surface of the void in a direction parallel to the applied electric field $[8,9]$. When a discharge reaches the void surface, it is assumed to propagate along the void top and bottom surface $[10,11]$.

Since discharges can occur randomly within the void, a discharge is modelled to occur within any of the 9 regions on the void surface. When the field in any of the void region, $E_{\text {voidx }}$, where $x$ equals to 1 to 9 , exceeds the inception field, $E_{\text {inc }}$, a discharge may occur provided that a free initial electron exists within the void. When a discharge occurs from top to bottom void surface in one of the 9 regions, the charge density on the top surface of that region is added with $+\rho$ while the bottom surface is increased with $-\rho$. Then, $E_{\text {voidx }}$ is compared with the extinction field, $E_{\text {ext }}$. If $E_{\text {voidx }}$ is less than $E_{\text {ext }}$ a discharge stops. Else, another $-\rho$ and $+\rho$ are added on the bottom and top surface respectively within that region. The opposite is done when a discharge occurs from bottom to top void surface $[8,9]$.

In this model, when a discharge occurs at certain time, each discharge is assumed to occur only in one region and not in multi regions. If a discharge occurring in multi regions is considered, it will increase the complexity of the modelling as more parameters need to be considered and may increase the simulation time.

In the void, the availability of an initial electron is modelled by electron surface emission and volume ionisation. For electron surface emission, the number of electrons available, $F_{s x}(t)$ at time $t$ in region $x$ is calculated using [12-14]

$$
\begin{aligned}
N_{e s}(t)= & v_{0} \kappa\left(q_{x} / e\right) \exp \left[-\left(t-t_{D x}\right) / \tau\right] \\
& \exp \left[-\left(\Phi-\sqrt{e E_{\text {voidx }}(t) /\left(4 \pi \varepsilon_{0}\right)}\right) /(k T)\right]
\end{aligned}
$$

where $t_{D x}$ is the time passed since the last discharge in region $x, \tau$ is the time constant of charge decay, $\kappa$ is the electron detrapping constant, $q_{x}$ is the last discharge charge magnitude in region $x, e$ is the charge of elementary, $\varepsilon_{0}$ is the vacuum permittivity, $v_{0}$ is the fundamental phonon frequency, $\Phi$ is the material surface work function, $E_{\text {voidx }}(t)$ is the void field magnitude in region $x, T$ is the temperature in the void and $k$ is the Boltzmann's constant. 
From equation (1), $\left(q_{x} / e\right)$ is the number of charge presents on the void surface in region $x$ due to the previous discharge. The charge decay on the surface in region $x$ is represented by the term $\exp \left[-\left(t-t_{D x}\right) / \tau\right]$. The last exponential term indicates that initial free electron due to surface emission depends on the void field in region $x$, temperature and the surface work function.

Electron emission due to volume ionisation process in each region, $F_{v x}$, is determined using [12-14]

$$
F_{v x}=(1 / 9)\left[\pi w^{2} h C_{r a d} \Phi_{r a d}(\rho / p)_{0} p\left(1-v^{-\beta}\right)\right]
$$

where $w$ is the void width, $h$ is the void height, $C_{r a d}$ is the interaction between gas and radiation characterisation, $\Phi_{r a d}$ is the flux density of radiation quantum, $(\rho / p)_{0}$ is the gas pressure reduced density, $p$ is the void pressure, $v$ is the overvoltage ratio and $\beta$ is the coefficient of gas characterisation. $C_{r a d} \Phi_{r a d}=2 \times 10^{6}$ $\mathrm{kg}^{-1} \mathrm{~s}^{-1},(\rho / p)_{0}=10^{-5} \mathrm{kgm}^{-3} \mathrm{~Pa}^{-1}, \beta=2$ for air Since there are 9 regions in the void, (1/9) is included in equation (2). The initial free electron available, $F_{x}(t)$ at time $t$ is determined by $F_{s x}(t)+F_{v x}$. $F_{v x}$ is time independent because volume ionisation does not depend on the void field.

The probability of a discharge to happen in region $x$ is calculated using $[15,16]$

$P_{x}(t)=F_{x}(t) \Delta t$

where $\Delta t$ is the time step. Since discharge can occur randomly in the void, $P_{x}(t)$ is checked with a randomly generated decimal number, $N$, which is within 0 and 1 . If $P_{x}(t)>N$, a discharge could occur in region $x$. A discharge could also occur in any other regions having $P_{x}(t)>N$ at the same instant.

The apparent charge magnitude, $q_{D}$ is determined using

$q_{\text {app }}=\int\left(\rho_{\text {after }}-\rho_{\text {before }}\right) d S$

where $\rho_{\text {after }}$ and $\rho_{\text {affer }}$ are the charge density on the ground electrode before and after discharges occur and $S$ is the surface area of the ground electrode. $q_{D}$ is the apparent discharge magnitude due to single or simultaneous discharge occurrences in the void at time $t$.

The real charge magnitude in region $x, q_{x}$, is calculated by

$q_{x}=\int\left(\rho_{\text {xafter }}-\rho_{\text {xbefore }}\right) d S_{x}$

where $\rho_{\text {xaffer }}$ and $\rho_{\text {xafter }}$ are the charge density on region $x$ before and after a PD occur and $S_{x}$ is the surface area of region $x$.

The inception voltage, $V_{i n c}$ is determined from the measurement while the void inception field, $E_{\text {inc }}$ is determined from the simulation model. $E_{\text {inc }}$ is the value of the void field when the voltage amplitude equals to $V_{\text {inc }}$. The effect of charge decay by conduction on the void surface was neglected due to its effect in the modelling is not significant.

In the model geometry, where $\varepsilon$ is the permittivity, the electric field distribution $E$ is solved using

$\varepsilon \nabla \bullet E=0$

\section{TEST OBJECT AND MEASUREMENT}

Figure 2 shows the measurement system used in this work. The system consists of an impulse voltage generation circuit, $V_{\text {impulse }}$, a test object and a partial discharge (PD) detection set. The discharge detection system that was used to record all discharge occurrences from the test object consists of a coupling capacitor, a measuring impedance, a discharge detector and a personal computer (PC). The coupling capacitor supplies charges to the electrodes on the test objects when discharges occur, the measuring impedance detects the current flow due to discharges, discharge detector changes the current signal into voltage signal and the USB controller provides the interface between the discharge detector and $\mathrm{PC}$.

From Figure 3, the impulse voltage generation circuit consists of a DC input voltage, $V_{D C}$, capacitance of discharge, $C_{1}$, capacitance of load, $C_{2}$, front or damping resistance, $R_{1}$, resistance of discharge, $R_{2}$ and a spark gap, $G$. The peak magnitude of the output impulse voltage was varied by changing the peak DC input voltage. The front time and tail time of the voltage were changed by varying the value of $R_{1}$ and $R_{2}$ respectively.

Referring to Figure 4, the test object consists of a rectangular void of $6 \mathrm{~mm}$ width and height of $2 \mathrm{~mm}$ located in the middle of polyethylene (PE) insulation material of $5 \mathrm{~cm}$ diameter and height $6 \mathrm{~mm}$. The void was created by sandwiching three layers of PE of $2 \mathrm{~mm}$ thickness each, where the centre layer has a rectangular void. The whole test object including the electrodes was soaked in silicon oil to avoid discharges along the test object surface. The test object was applied with an impulse voltage on the upper electrode and the bottom electrode was kept grounded.

Three experiments were conducted. The first experiment was varying the peak magnitudes of the impulse voltage applied on the test object from 60 to $90 \mathrm{kV}$ with an increment of $10 \mathrm{kV}$ while keeping the front time to tail time ratio with $1.2 / 50$ us. The second experiment was varying the front time of the impulse voltage with $1.2,2,5$ and 10 us while keeping the peak magnitude at $60 \mathrm{kV}$ and tail time with 50 us. The final experiment was varying the tail time of the impulse voltage with

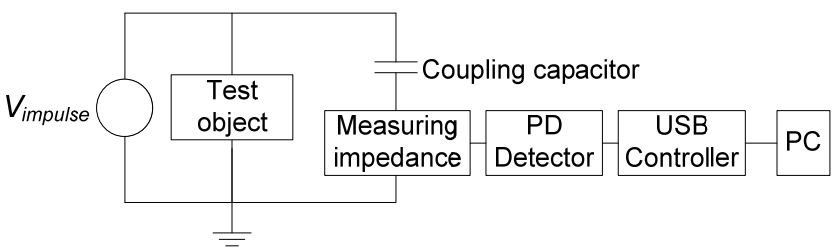

Figure 2. Complete measurement system.

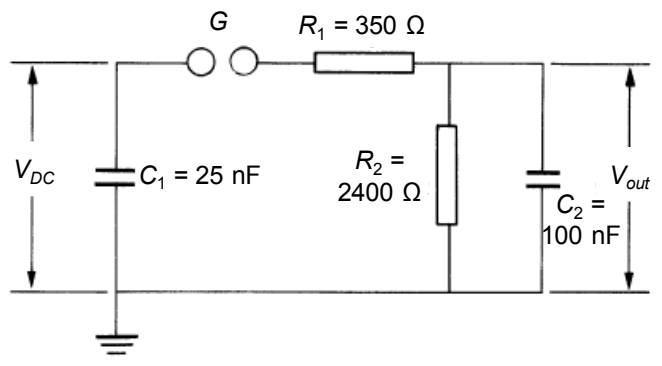

Figure 3. Impulse voltage generator circuit 


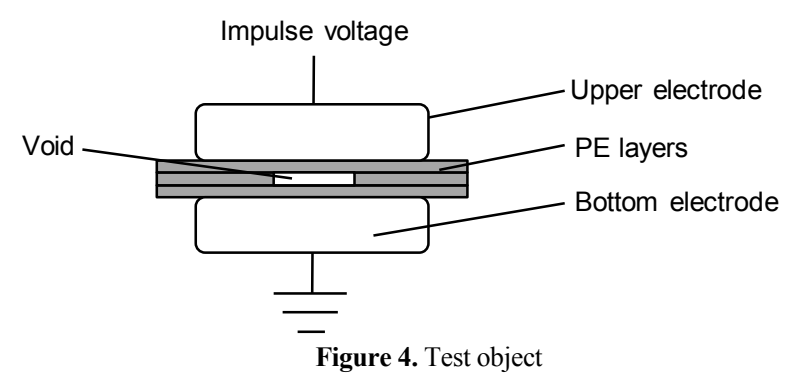

5, 50, 100 and 200 us while keeping the peak magnitude at $60 \mathrm{kV}$ and front time with 1.2 us. For each applied impulse voltage, the measurement was taken for $10 \mathrm{~s}$. Charge amplitude vs. time graph, the number of discharges per ms, total charge per ms, minimum charge and maximum charge magnitude were recorded.

\section{RESULTS}

The simulation and measurement results that have been obtained are presented in this section. The results consist of measurement and simulation on void discharges under different peak magnitude of impulse voltage, front time and tail time of the applied impulse voltage.

\subsection{SIMULATION OF ELECTRIC FIELD DISTRIBUTION}

Figure 5 shows the distribution of the electric field in the model that has been developed before and after a discharge occurs automatically in region 5 at 2 us and region 9 at 6 us. The parameters used in the simulation are shown in Table 1. Referring to Figure 5a, before any discharge happens in the void, the void field is uniform and higher than the insulation material. This is due to the void permittivity is less than the insulation material. However, after the first discharge occurred in region 5, the field in region 5 decreases but the electric field in the region where discharge does not occur remains higher than in the insulation material (Figure 5b). This is due to the charge accumulated on the top and bottom void surfaces in region 5 has a field of opposite direction from the applied field. The electric field within the nearby regions is slightly affected.

In Figure 5c, a discharge occurs in region 9 at 6 us when Evoid9 is higher than $E_{i n c}$ and $P_{9}(t)>N$. When a discharge occurs in region 9 , the electric field in region 9 decreases, which is similar to the case when discharge occurred in region 5 . The electric field in other regions remains higher than in the insulation material, except for regions 5 and 9. This is due to charge accumulated on region 9 and region 5. Thus, variation of void surface charge accumulation will yield variation of the electric field distribution on the void surface, which will affect the occurrence of subsequent discharges.

The parameter values of the simulation for all measurement results are shown in Table 1. The values were obtained as follows; the time stepping interval, $\Delta t$ was set as 0.1 us so that the electric field in the simulation will not change too fast with one time step, which in turn affecting the simulation results greatly. However, if $\Delta t$ is set too small, the simulation time will be increased greatly. The void temperature and pressure were assigned as room temperature and atmosphere pressure. The time constant of charge decay, $\tau$ was set as $2 \mathrm{~ms}$ since it was used in one of the past literatures [13]. The electron detrapping constant,

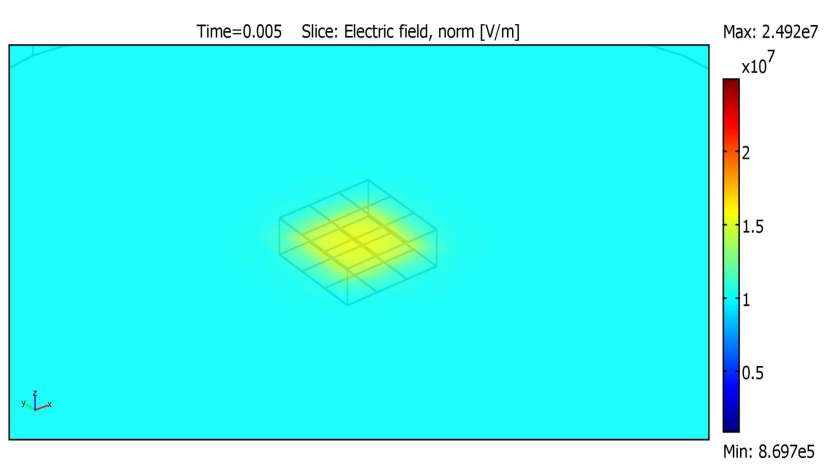

(a)

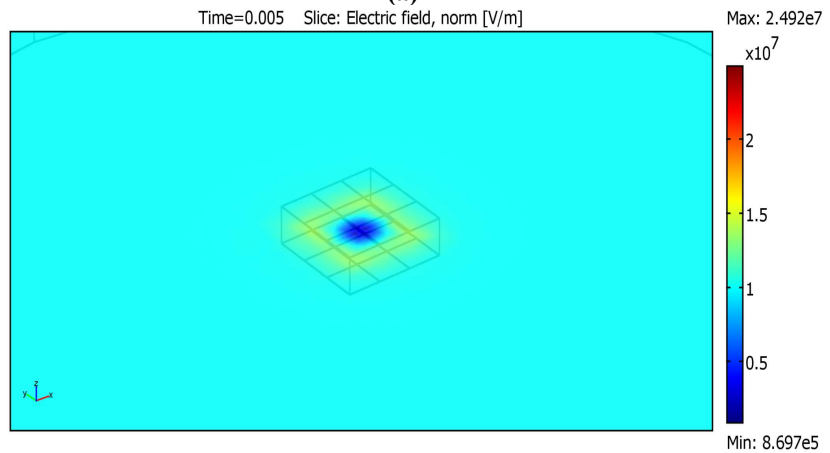

(b)

Time $=0.005$ Slice: Electric field, norm $[\mathrm{V} / \mathrm{m}]$ Max: $2.492 \mathrm{e} 7$

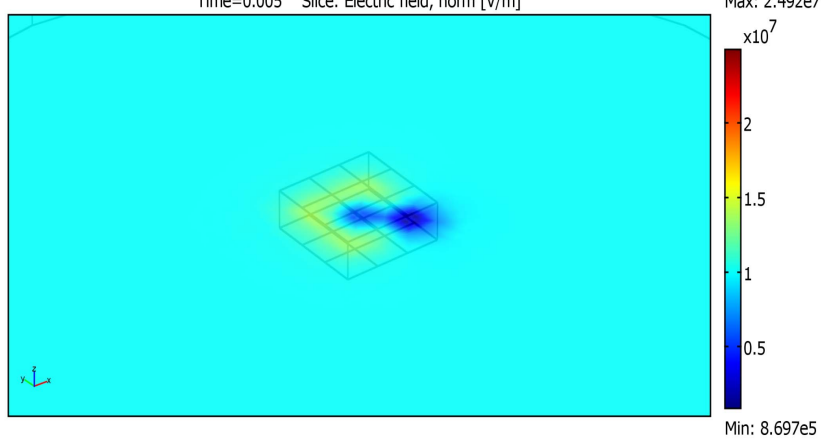

(c)

Figure 5. Distribution of electric field in the model; (a) before, (b) after a discharge in region 5 and (c) after a discharge occurs in region 9

Table 1. Simulation parameters.

\begin{tabular}{|c|c|}
\hline Parameter & Value \\
\hline Void height, $h$ & $2 \mathrm{~mm}$ \\
\hline Void width, $w$ & $6 \mathrm{~mm}$ \\
\hline Applied impulse voltage condition & $\begin{array}{c}\text { Test } 1: 1.2 / 50 \text { us with } 60 \mathrm{kV}, 70 \mathrm{kV} \text {, } \\
80 \mathrm{kV} \text { and } 90 \mathrm{kV} \\
\text { Test } 2: 60 \mathrm{kV} \text { with } 1.2 / 50 \mathrm{us}, 2 / 50 \mathrm{us} \text {, } \\
5 / 50 \mathrm{us} \text { and } 10 / 50 \mathrm{us} \\
\text { Test } 3: 60 \mathrm{kV} \text { with } 1.2 / 5 \mathrm{us}, 1.2 / 50 \mathrm{us} \text {, } \\
1.2 / 100 \mathrm{us} \text { and } 1.2 / 200 \mathrm{us}\end{array}$ \\
\hline Time stepping interval, $\Delta t$ & $0.1 \mathrm{us}$ \\
\hline Void temperature, $T$ & $293 \mathrm{~K}$ \\
\hline Void pressure, $p$ & $100 \mathrm{kPa}$ \\
\hline Inception field of the void, $E_{i n c}$ & $3.41 \mathrm{kVmm}^{-1}$ \\
\hline Extinction field, $E_{e x t}$ & $1 \mathrm{kVmm}^{-1}$ \\
\hline Surface charge density increment, $\rho$ & $1 \times 10^{-4} \mathrm{Cm}^{-1}$ \\
\hline Time constant if charge decay, $\tau$ & $2 \mathrm{~ms}$ \\
\hline Surface work function, $\Phi$ & $1.2 \mathrm{eV}$ \\
\hline Electron detrapping constant, $\kappa$ & 1 \\
\hline
\end{tabular}

$\kappa$ was set as 1 since it was found that it does not influence the simulation results. The inception field, $E_{i n c}$ is the value of the field in the void when the voltage amplitude equals to the 
inception voltage from the measurement. The extinction field, $E_{\text {ext }}$ was obtained through comparison between the measured and simulated minimum apparent charge magnitude. The surface charge density increment, $\rho$ was set as $1 \times 10^{-4} \mathrm{Cm}^{-1}$ so that the reduction of the electric field in the void, $E_{\text {void }}$ during $\mathrm{PD}$ occurrence is not too fast or too slow. If $\rho$ is set too high, PD will stop at the field level too low from $E_{\text {ext }}$ while a too small value will increase the simulation time greatly.

The only parameter which was tuned to fit the experimental results is the surface work function, $\Phi$. For each $\Phi$ value, the total mean square error (MSE) between simulation and measurement in terms of the charge magnitude vs. time distribution and the error in the total number of PDs between simulation and measurement were calculated. The value of $\Phi$ which yields the lowest total MSE and error in the total number of PDs was selected for the simulation. Hence, this ensures that only one value is most suitable for $\Phi$, which yields the closest match between the measurement and simulation results.

\subsection{ELECTRIC FIELD MAGNITUDE VS. TIME}

The simulation of the field magnitude in regions 1,5 and 9 vs. time under $60 \mathrm{kV}$ peak applied impulse voltage is shown in Figure 6. Region 1 is chosen to be displayed in Figure 6 in order to observe how the electric field in the regions where no discharge occurs are affected by discharges in regions adjacent to them. Regions 5 and 9 are also shown in Figure 6 to further explain the electric field behaviour in Section 4.1.

During the rise time of the applied voltage, the electric field in region 1, 5 and 9, $E_{\text {voidl }}, E_{\text {voids }}$ and $E_{\text {void } 9}$ increase with the applied voltage. $E_{0}$ is the void field when there is no discharge occurs at all. $E_{0}$ is used as a reference to compare the void field with and

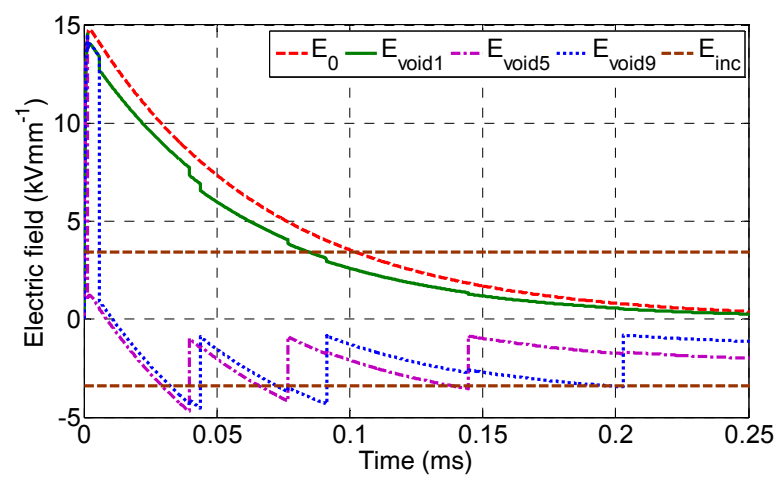

(a)

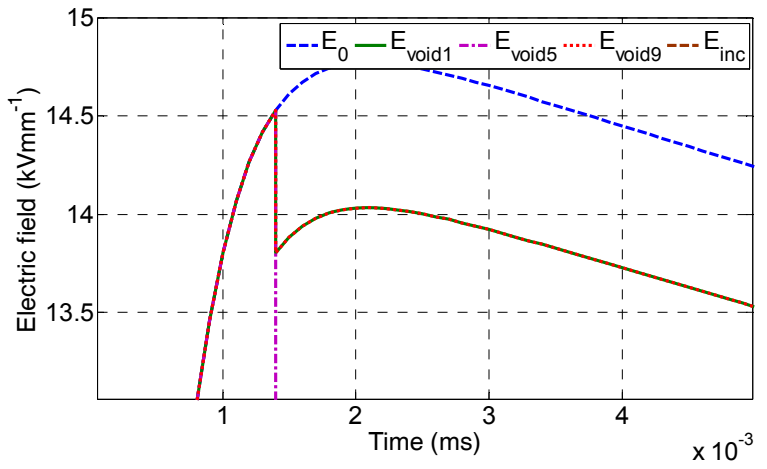

(b)

Figure 6. Simulated electric field magnitude vs. time under applied impulse voltage; (a) normal view and (b) zoomed in view without discharges. At 2 us, a discharge occurs in region 5, resulting in $E_{\text {voids }}$ to reduce sharply until it is lower than the extinction field, $E_{\text {ext }}$. This is due to the charge accumulation on top and bottom void surfaces in region 5 has an electric field which the direction is opposite of $E_{\text {voids }}$.

The first discharge occurs in region 5 only after the inception field, $E_{\text {inc }}$ is greatly passed. This is caused by the delay of getting initial electron to initiate a discharge since the applied voltage is rising too fast. At the same instant, it can be seen in Figure 6b that $E_{\text {void } 1}$ and $E_{\text {void } 9}$ are affected by the discharge in region 5, where they decrease slightly due to the influence of charge accumulation in region 5.

At 6 us, the first discharge occurs in region 9, resulting in $E_{\text {void } 9}$ to decrease sharply while $E_{\text {void } 1}$ and $E_{\text {voids }}$ are slightly reduced. After 10 us, both $E_{\text {voids }}$ and $E_{\text {voidg }}$ change direction, as shown by the negative sign of the electric field in Figure 6a. Discharge occurs in region 5 and 9 when $E_{i n c}$ is exceeded. No discharge occurs after $0.21 \mathrm{~ms}$ because $E_{\text {voidl }}, E_{\text {void } 5}$ and $E_{\text {void9 }}$ remain lower than $E_{\text {inc }}$ due to the applied voltage is approaching zero.

\subsection{TEST 1: VOID DISCHARGES UNDER VARIOUS PEAK MAGNITUDE OF IMPULSE VOLTAGE}

Figure 7 shows measurement and simulation results of charge magnitude vs. time from void discharges under different peak magnitude of the applied impulse voltage while Table 2 shows discharge data of measurement and simulation results. The front/tail time was fixed at 1.2/50 us. From the measurement patterns, discharges with positive charge magnitude and significantly higher than subsequent discharges occurred during the rise time of the applied voltage. During the fall time, negative discharges of lower charge magnitude occurred. The explanations of these occurrences have been detailed in Section 4.2.

Referring to the measurement data in Table 2, the number of discharges per ms, total charge per $\mathrm{ms}$ and maximum charge magnitude are larger at higher impulse voltage peak. The number of discharges per ms increases with the impulse voltage peak due to the slope during the voltage rise time is higher. This causes the time when the void field reaches the inception field is shorter compared to lower impulse voltage peak. Hence, more discharges can happen during the rise time of higher applied voltage peak. Higher applied impulse voltage peak also causes the duration of the void field remains higher than the inception field during the voltage fall time. Hence, more discharges can

Table 2. Measurement (M) and simulation (S) results under different peak magnitude of the applied impulse voltage (front/tail time of 1.2/50 us).

\begin{tabular}{c|c|c|c|c|c}
\hline $\begin{array}{c}\text { Peak } \\
\text { magni } \\
\text { tude } \\
\text { (kV) }\end{array}$ & $\begin{array}{c}\text { Number of } \\
\text { discharges } \\
\text { per ms }\end{array}$ & $\begin{array}{c}\text { Total } \\
\text { charge } \\
\text { magnitude } \\
\text { per ms } \\
\text { (pC) }\end{array}$ & $\begin{array}{c}\text { Maximum } \\
\text { charge } \\
\text { magnitude } \\
\mathbf{( p C )}\end{array}$ & $\begin{array}{c}\text { Minimum } \\
\text { charge } \\
\text { magnitud } \\
\mathbf{e}(\mathbf{p C})\end{array}$ \\
\hline 60 & $\mathrm{M}$ & 37 & 13467.17 & 896.28 & 166.14 \\
& $\mathrm{~S}$ & 36 & 13596.34 & 902.16 & 164.4 \\
70 & $\mathrm{M}$ & 42 & 16065.5 & 1038.29 & 158.72 \\
& $\mathrm{~S}$ & 42 & 16638.51 & 1061.28 & 158.52 \\
80 & $\mathrm{M}$ & 47 & 19838.68 & 1222.27 & 159.49 \\
& $\mathrm{~S}$ & 48 & 20403.67 & 1213.48 & 158.77 \\
90 & $\mathrm{M}$ & 54 & 23369.12 & 1388.67 & 159.86 \\
& $\mathrm{~S}$ & 53 & 22766.09 & 1386.89 & 169.06 \\
\hline
\end{tabular}


occur during the fall time. As a result, the overall number of discharges per ms becomes higher with higher impulse voltage peak.

The maximum charge magnitude is larger at higher impulse voltage peak due to the maximum void field can achieve higher value. When a discharge happens, the void field reduction is also larger, resulting in larger charge magnitude. The total charge magnitude per ms increases with the impulse voltage peak. This is due to the number of discharges per ms and the maximum charge magnitude are higher. The measured inception voltage does not change with the impulse voltage peak. The reason is the inception voltage is strongly dependent on the size and shape of the void, the material thickness and material type. This finding is also tally with the mathematical equation of inception voltage as reported in previous literature $[12,13]$, where the inception voltage does not depend on the peak of the applied voltage.
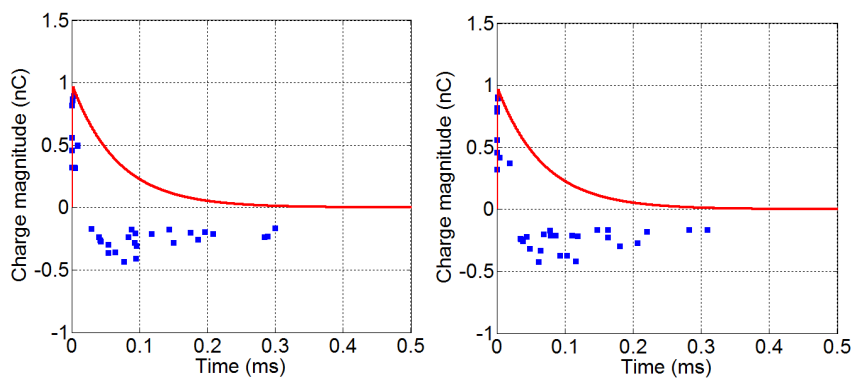

(a)
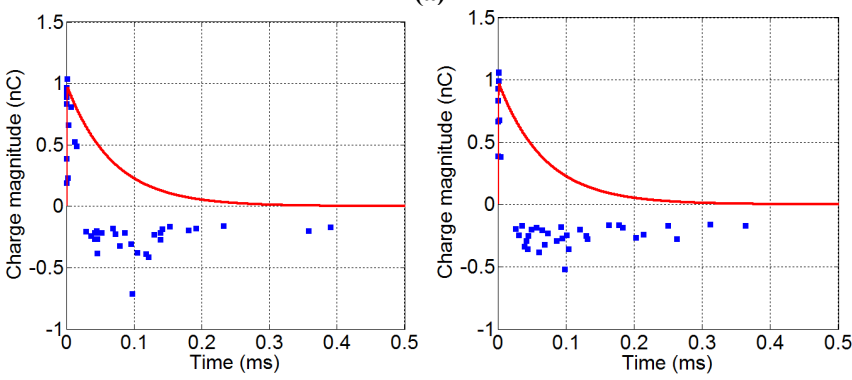

(b)
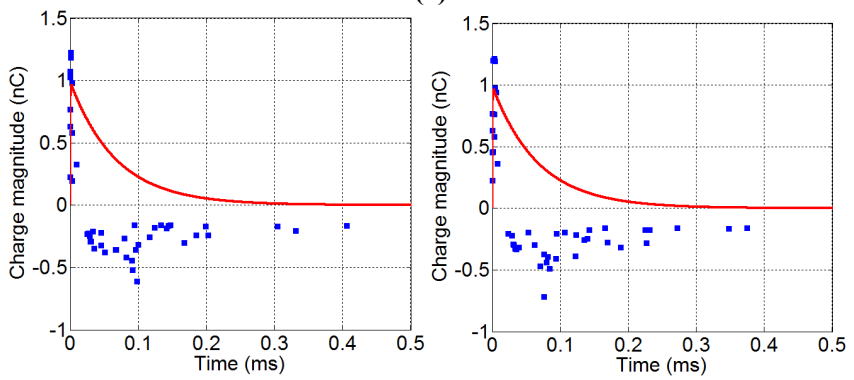

(c)
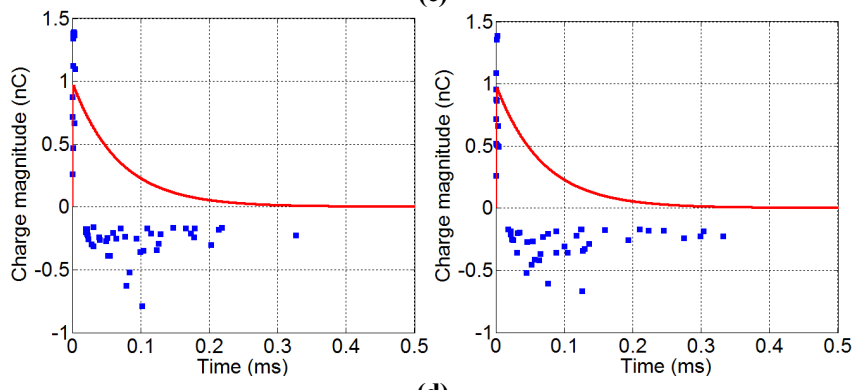

(d)

Figure 7. Measurement (left) and simulation (right) of charge magnitude vs. time under different applied impulse voltage; (a) $60 \mathrm{kV}$, (b) $70 \mathrm{kV}$, (c) $80 \mathrm{kv}$ and (d) $90 \mathrm{kV}$ (front/tail time of $1.2 / 50$ us)
Referring to Figure 7 and Table 2, both simulation and measurement results are within acceptable agreement. This reasonable agreement was achieved by using parameter values as shown in Table 1 . The maximum charge magnitude from the simulation was achieved through a suitable value of the surface work function, $\Phi$, which is part of the electron surface emission and the extinction field, $E_{\text {ext }}$. The measured minimum charge magnitude was achieved in the simulation by setting a suitable extinction field value, $E_{\text {ext }}$. This is due to the charge magnitude depends on the magnitude field change in the void when a discharge occurs. The measured and simulated number of discharges per ms were matched by tuning the surface work function, $\Phi$ and the electron detrapping constant, $\kappa$ in the simulation model. Hence, some parameters in the model control more than one discharge characteristics under impulse voltage.

The void inception field, $E_{i n c}$ was determined from the simulation model, where it is the value of the void field when the applied voltage equals to measured inception voltage, $V_{i n c}$. In eq. (1), the pressure, $p$ and temperature, $T$ in the void were assumed to be atmosphere pressure and $293 \mathrm{~K}$. The charge decay time constant, $\tau$ was set as $2 \mathrm{~ms}$ because this value is a commonly used in literatures $[12,13]$. The increment of charge density, $\rho$ was chosen as $1 \times 10^{-4} \mathrm{Cm}^{-2}$. This is the most suitable value to model the charge density increment on the void surface at every time step when a discharge occurs in certain region. A too large $\rho$ may cause the void field, $E_{\text {void }}$, to drop too fast and stops far less than the extinction field, $E_{\text {ext }}$. However, a small $\rho$ may cause the simulation period to be very long due to a small decrement of $E_{\text {void }}$ at every time step during a discharge occurrence.

\subsection{TEST 2: VOID DISCHARGES UNDER VARIOUS FRONT TIME OF IMPULSE VOLTAGE}

Figure 8 and Table 3 show the measurement and simulation results of charge magnitude vs. time from void discharges under various front time of the applied voltage but keeping the peak magnitude and tail time constant at $60 \mathrm{kV}$ and 50 us respectively. Referring to the charge magnitude vs. time patterns in Figure 8, when the front time is longer, the number of discharges increases during the voltage rise time but the number of discharges during the fall time remains almost constant.

Longer front time allows longer period for the void field to be higher than the inception field. Thus, more discharges can happen during the rise time, causing discharges per ms and total charge magnitude per ms to become higher, as shown in Table 3.

Table 3. Measurement (M) and simulation (S) results under various front time of $60 \mathrm{kV}$ applied impulse voltage (tail time of $50 \mathrm{us}$ ).

\begin{tabular}{c|c|c|c|c|c}
\hline $\begin{array}{c}\text { Front/ } \\
\text { tail } \\
\text { time } \\
\text { (us) }\end{array}$ & $\begin{array}{c}\text { Number of } \\
\text { discharges } \\
\text { per ms }\end{array}$ & $\begin{array}{c}\text { Total } \\
\text { charge } \\
\text { magnitude } \\
\text { per ms } \\
\text { (pC) }\end{array}$ & $\begin{array}{c}\text { Maximum } \\
\text { charge } \\
\text { magnitude } \\
\mathbf{( p C )}\end{array}$ & $\begin{array}{c}\text { Minimum } \\
\text { charge } \\
\text { magnitud } \\
\mathbf{e}(\mathbf{p C})\end{array}$ \\
\hline $1.2 / 50$ & $\mathrm{M}$ & 37 & 13467.17 & 896.28 & 166.14 \\
& $\mathrm{~S}$ & 36 & 13596.34 & 902.16 & 164.4 \\
$2 / 50$ & $\mathrm{M}$ & 38 & 13756.19 & 884.71 & 163.72 \\
& $\mathrm{~S}$ & 39 & 13477.38 & 872.87 & 161.41 \\
$5 / 50$ & $\mathrm{M}$ & 41 & 14059.85 & 749.83 & 162.12 \\
& $\mathrm{~S}$ & 42 & 13593.97 & 784.63 & 159.08 \\
$10 / 50$ & $\mathrm{M}$ & 45 & 14163.25 & 633.84 & 159.46 \\
& $\mathrm{~S}$ & 43 & 13966.53 & 684.97 & 160.35 \\
\hline
\end{tabular}



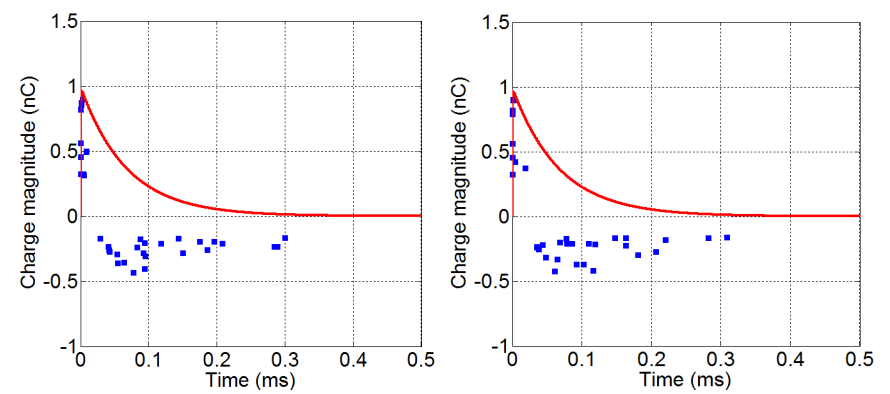

(a)
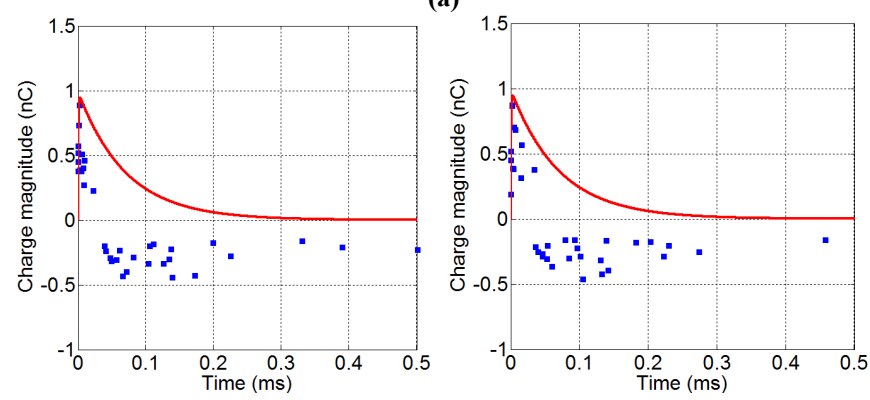

(b)
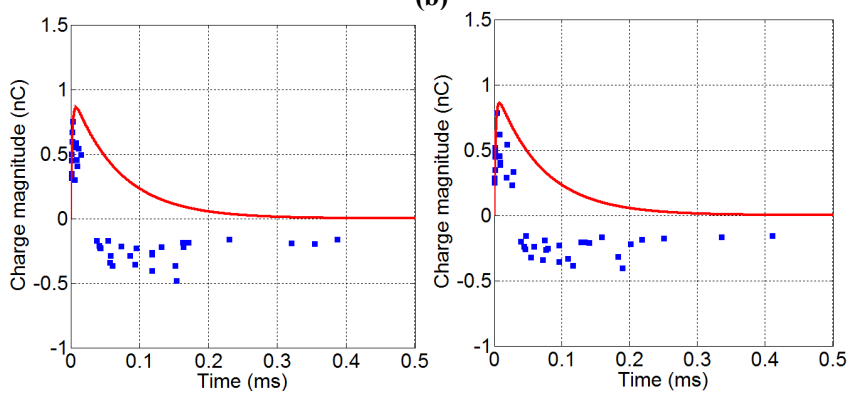

(c)
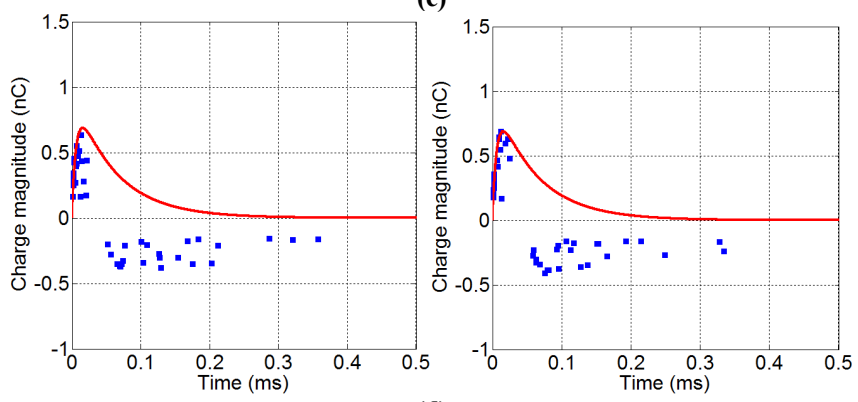

(d)

Figure 8. Measurement (left) and simulation (right) of charge magnitude vs. time under various front time of the applied impulse voltage; (a) 1.2/50 us, (b) $2 / 50$ us, (c) $5 / 50$ us and (d) 10/50 us (peak magnitude of $60 \mathrm{kV}$ )

When the front time of the impulse voltage is longer, the maximum discharge magnitude decreases. This is due to the rise rate of the impulse voltage is slower, resulting in shorter time delay of getting free electron to initiate a discharge. Hence, discharges occur almost exactly after the inception field is passed, resulting in smaller discharge magnitude. However, the minimum charge magnitude remains almost constant under different front time.

\subsection{TEST 3: VOID DISCHARGES UNDER VARIOUS TAIL TIME OF IMPULSE VOLTAGE}

The measurement and simulation results of charge magnitude vs. time from void discharges under different tail time of the impulse voltage while keeping the peak magnitude at $60 \mathrm{kV}$ and front time with 1.2 us are shown in Figure 9 and Table 4. Referring to Figure 9, when the tail time of the applied voltage is longer, more discharges occur during the fall time while the number of discharges during the rise time does not change significantly. Hence, the pattern becomes different only at the fall time but remain the same at the rise time with longer tail time. When the tail time is longer, the time for the void field to be higher than the inception field is longer. Hence, more discharges can happen during the fall time, resulting in the number of discharges per ms and total charge per ms to become higher.

However, the maximum discharge magnitude remains almost constant. This is due to the peak of the applied voltage and front time remains the same. The minimum charge magnitude also does
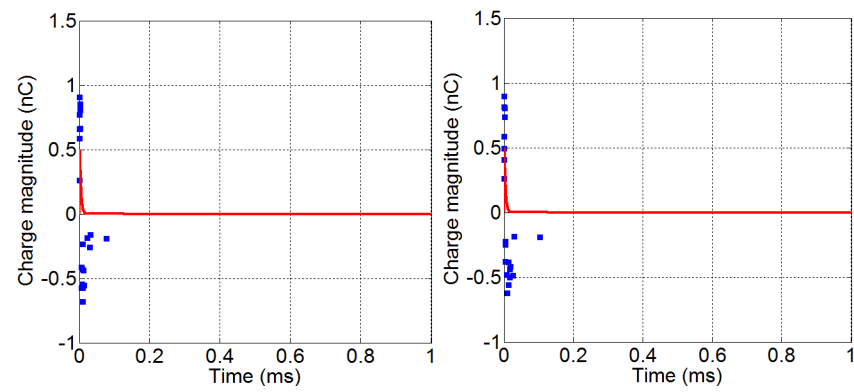

(a)
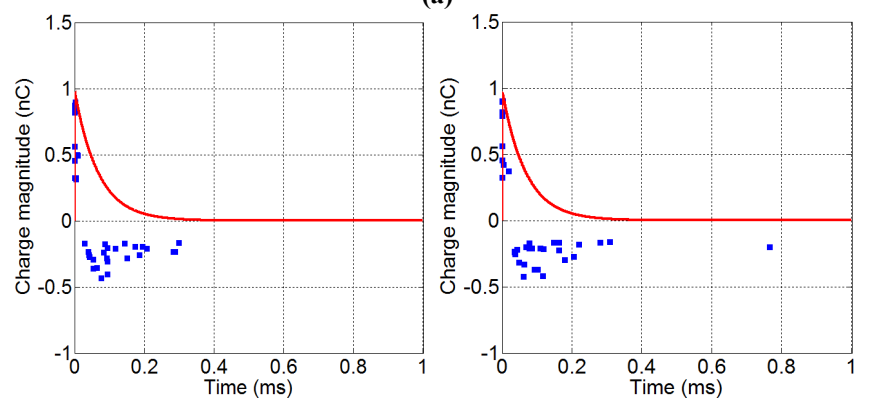

(b)
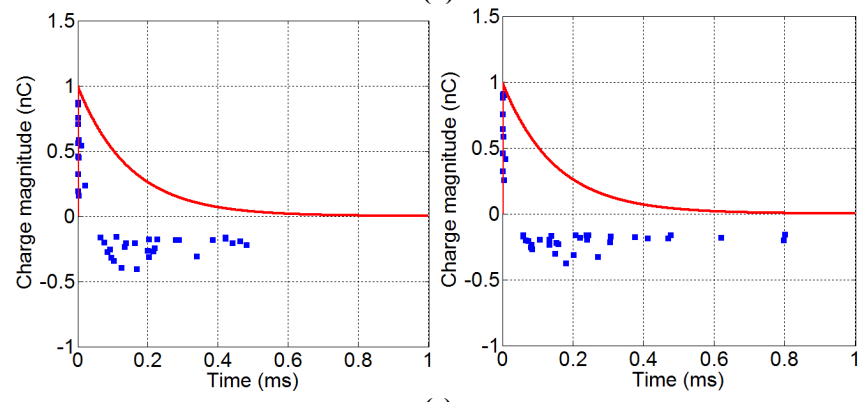

(c)
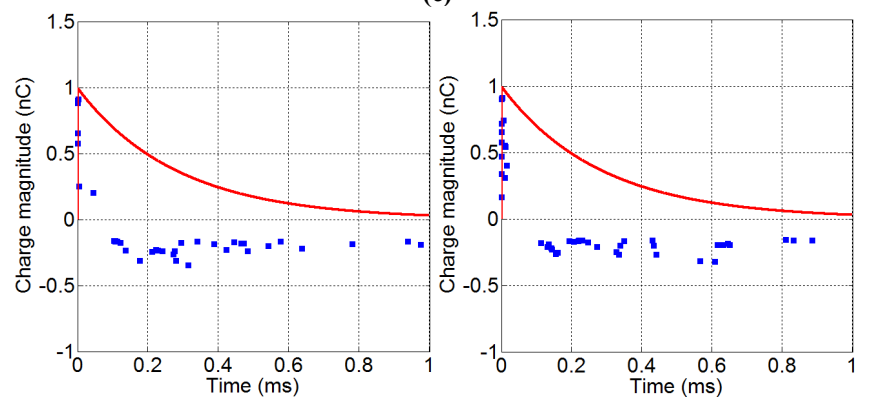

(d)

Figure 9. Measurement (left) and simulation (right) of charge magnitude vs. time under different tail time of the applied impulse voltage; (a) $1.2 / 5$ us, (b) $1.2 / 50$ us, (c) $1.2 / 100$ us and (d) $1.2 / 200$ us (peak magnitude of $60 \mathrm{kV}$ ) 
Table 4. Measurement $(\mathrm{M})$ and simulation $(\mathrm{S})$ results under different tail time of $60 \mathrm{kV}$ impulse voltage (front time of $1.2 \mathrm{us}$ ).

\begin{tabular}{c|c|c|c|c|c}
\hline $\begin{array}{c}\text { Front/ } \\
\text { tail } \\
\text { time } \\
\text { (us) }\end{array}$ & & $\begin{array}{c}\text { Number of } \\
\text { discharges } \\
\text { per } \mathbf{m s}\end{array}$ & $\begin{array}{c}\text { Total } \\
\text { charge } \\
\text { magnitude } \\
\text { per ms } \\
\text { (pC) }\end{array}$ & $\begin{array}{c}\text { Maximum } \\
\text { charge } \\
\text { magnitude } \\
(\mathbf{p C})\end{array}$ & $\begin{array}{c}\text { Minimum } \\
\text { charge } \\
\text { magnitud } \\
\mathbf{e}(\mathbf{p C})\end{array}$ \\
\hline \multirow{2}{*}{$1.2 / 50$} & $\mathrm{M}$ & 22 & 11597.83 & 905.24 & 160.75 \\
& $\mathrm{~S}$ & 23 & 11108.5 & 896.92 & 185.51 \\
$2 / 50$ & $\mathrm{M}$ & 37 & 13467.17 & 896.28 & 166.14 \\
& $\mathrm{~S}$ & 36 & 13596.34 & 902.16 & 164.4 \\
$5 / 50$ & $\mathrm{M}$ & 42 & 14131.27 & 872.61 & 159.4 \\
& $\mathrm{~S}$ & 43 & 14239.25 & 911.8 & 158.71 \\
$10 / 50$ & $\mathrm{M}$ & 44 & 14842.63 & 910.03 & 161.18 \\
& $\mathrm{~S}$ & 44 & 13773.89 & 908.82 & 161.56 \\
\hline
\end{tabular}

not change significantly. Hence, the tail time does not influence the delay of getting free electron to initiate a discharge.

As shown in Figure 9 and Table 4, the simulation and measurement results are within acceptable agreement between each other. The measurement results were reproduced successfully by the simulation using parameter values as shown in Table 2.

\section{CONCLUSIONS}

The characteristics of void discharge occurrences within dielectric insulation material under impulse voltage have been successfully investigated in this work. Discharge characteristics are strongly dependent on the applied impulse voltage shape. From the measurement work, the number of discharges per $\mathrm{ms}$ and total charge magnitude per $\mathrm{ms}$ are larger at higher peak magnitude, longer front time and longer tail time of the applied impulse voltage. The maximum charge magnitude is larger at higher peak magnitude and shorter front time of the impulse voltage. More discharges tend to happen during the fall time than the rise time of the applied voltage. No discharge occurs when the applied voltage reaches zero value.

A three-dimensional model geometry of a rectangular void in a dielectric material was also successfully developed using finite element method. The model was able to simulate occurrences of discharge and reproduced the measurement results that have been obtained. Comparison between the simulation data and measurement results revealed that some physical parameters are affecting the occurrence of discharges within a rectangular void in an insulation material under applied impulse voltage. The parameters include the surface charge density, surface work function, inception field and extinction field. Variation of charge distribution on the void surface was also successfully simulated through modelling of discharges within various regions on the void surface. The occurrence of subsequent discharge depends on the surface charge distribution. Through this work, a better understanding on void discharge characteristics within dielectric material under applied impulse voltage has been achieved.

\section{ACKNOWLEDGEMENT}

The authors thank the University of Malaya and Malaysian Ministry of Education for supporting this work through the UMRG and FRGS research grants (Grant no: RG135/11AET and FP026-2012A) and HIR research grant (H-16001-D00048).

\section{REFERENCES}

[1] T. Do, O. Lesaint, and J. L. Auge, "Streamers and partial discharge mechanisms in silicone gel under impulse and AC voltages," IEEE Trans. Dielectr. Electr. Insul., Vol. 15, pp. 1526-1534, 2008.

[2] L. Junhao, Z. Liang, L. Jianfeng, Y. Xiu, and L. Yanming, "Partial discharge characteristics over $\mathrm{SF}_{6} /$ epoxy interfaces under impulse voltage," IEEE Trans. Dielectr. Electr. Insul., Vol. 20, pp. 2158-2164, 2013.

[3] Z. Xuefeng, Y. Xiu, G. Zhifeng, L. Junhao, S. Wenrong, and L. Yanming, "Characteristics and Development Mechanisms of Partial Discharge in $\mathrm{SF}_{6}$ Gas Under Impulse Voltages," IEEE Trans. Plasma Sci., Vol. 39, pp. 668674, 2011

[4] F. Guastavino, A. Dardano, and E. Torello, "Measuring partial discharges under pulsed voltage conditions," IEEE Trans. Dielectr. Electr. Insul., Vol. 15, pp. 1640-1648, 2008.

[5] S. Boggs, "Analytical approach to breakdown under impulse conditions," IEEE Trans. Dielectr. Electr. Insul., Vol. 11, pp. 90-97, 2004.

[6] C. Forssen and H. Edin, "Partial discharges in a cavity at variable applied frequency part 2: Measurements and modeling," IEEE Trans. Dielectr. Electr. Insul., Vol. 15, pp. 1610-1616, 2008.

[7] C. Forssen and H. Edin, "Partial discharges in a cavity at variable applied frequency part 1: Measurements," IEEE Trans. Dielectr. Electr. Insul., Vol. 15, pp. 1601-1609, 2008.

[8] H. A. Illias, M. A. Tunio, A. H. Abu Bakar, H. Mokhlis, and G. Chen, "Partial discharge behaviours within a void-dielectric system under square waveform applied voltage stress," IET Sci., Measurem. Technology, Vol. 8, pp. 81-88, 2014.

[9] H. A. Illias, G. Chen, A. H. A. Bakar, H. Mokhlis, and M. A. Tunio, "Partial discharges within two spherical voids in an epoxy resin," J. Phys. D: Appl. Phys., Vol. 46, pp. 1-10, 2013.

[10] W. Kai, S. Yasuo, and L. A. Dissado, "The contribution of discharge area variation to partial discharge patterns in disc-voids," J. Phys. D: Appl. Phys., Vol. 37, pp. 1815-1823, 2004.

[11] W. Kai, T. Okamoto, and Y. Suzuoki, "Effects of discharge area and surface conductivity on partial discharge behavior in voids under square voltages," IEEE Trans. Dielectr. Electr. Insul., Vol. 14, pp. 461-470, 2007.

[12] L. Niemeyer, "A generalized approach to partial discharge modeling," IEEE Trans. Dielectr. Electr. Insul., Vol. 2, pp. 510-528, 1995.

[13] F. Gutfleisch and L. Niemeyer, "Measurement and simulation of PD in epoxy voids," IEEE Trans. Dielectr. Electr. Insul., Vol. 2, pp. 729-743, 1995.

[14] R. Schifani, R. Candela, and P. Romano, "On PD mechanisms at high temperature in voids included in an epoxy resin," IEEE Trans. Dielectr. Electr. Insul., Vol. 8, pp. 589-597, 2001.

[15] H. Illias, G. Chen, and P. L. Lewin, "Partial Discharge Behavior within a Spherical Cavity in a Solid Dielectric Material as a Function of Frequency and Amplitude of the Applied Voltage," IEEE Trans. Dielectr. Electr. Insul., Vol. 18, pp. 432-443, 2011.

[16] H. Illias, G. Chen, and P. L. Lewin, "The influence of spherical cavity surface charge distribution on the sequence of partial discharge events," J. Phys. D: Appl. Phys., Vol. 44, pp. 1-15, 2011.

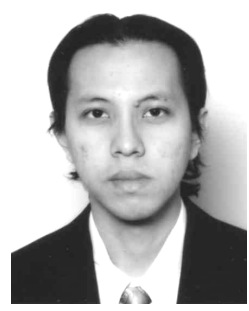

H.A. Illias was born in Kuala Lumpur, Malaysia in 1983. He received the Bachelor's degree in electrical engineering from the University of Malaya, Malaysia in May 2006 and the Ph.D. degree in electrical engineering from the University of Southampton, United Kingdom in 2011. He worked as a product engineer in Freescale Semiconductor Malaysia from 2006 to 2007. Since 2011, he has been a Senior Lecturer in the University of Malaya. His main research interests include partial discharge modeling and measurement in solid dielectrics and condition monitoring. 


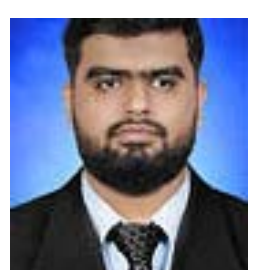

M. A. Tunio received his B.Eng. in electrical engineering in 2009 from Quaid-e-Awam University of Engineering, Science \& Technology, Pakistan and the M.Eng. degree in power system in 2011 from the University of Malaya, Malaysia. Since 2012, he has been a Research Assistant and Ph.D. student in the Department of Electrical Engineering, University of Malaya.

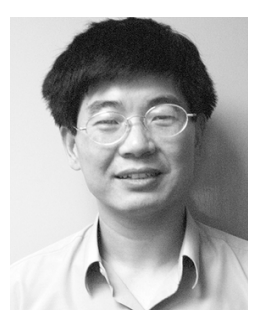

G. Chen was born in China in 1961 . He received the B.Eng. (1983) and M.Sc. (1986) degrees in electrical engineering from Xi'an Jiaotong University, China. After he obtained the Ph.D. degree (1990) from the University of Strathclyde, UK, he joined the University of Southampton as a postdoctoral research fellow and became a senior research fellow subsequently. In 1997 he was appointed as a research lecturer and promoted to a Reader in 2002 . He is now a professor of high voltage engineering at the

University of Southampton and a visiting professor of Xi'an Jiaotong University. His main research interests are electrical characterization of dielectric materials and electrical ageing. In the last twenty years, one of his key areas of research has been developing techniques for space charge measurement in polymeric materials and understanding its role in electrical ageing and breakdown. He has obtained financial support from EPSRC and UK industry, has been actively involved in IEEE, IEC and CIGRE activities and has authored over 100 journal papers and 250 international conference papers.

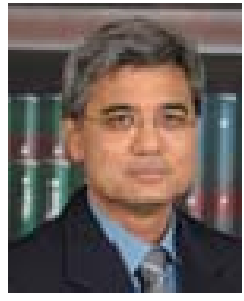

A. H.A. Bakar received his B.Sc. degree in electrical engineering in 1976 from University of Southampton, United Kingdom and the M.Eng. and Ph.D. degrees from the University Technology Malaysia in 1996 and 2003, respectively. He has 30 years of utility experiences in Malaysia before joining academia. Since 2009, he has been a Lecturer in the Department of Electrical Engineering, University of Malaya, Malaysia. In 2012, he joined the UM Power Energy Dedicated Advanced Centre (UMPEDAC), University of Malaya, Malaysia.

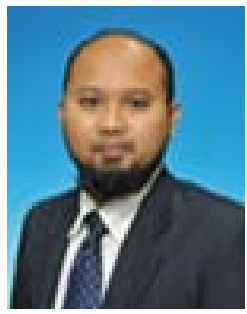

H. Mokhlis received his B.Eng. degree in electrical engineering in 1999 and the M.Eng.Sc. in 2002 from the University of Malaya, Malaysia. He obtained the $\mathrm{Ph} . \mathrm{D}$. degree from the University of Manchester, United Kingdom in 2009. Since 2009, he has been a Senior Lecturer in the Department of Electrical Engineering, University of Malaya. In 2014, he was promoted to an Associate Professor. 